\title{
Prováveis ocorrências de enclaves úmidos no alto sertão paraibano
}

\author{
Possible instances of damp enclaves in the alto sertão of Paraiba
}

\author{
Brandão ${ }^{1}$, M.H.M.; Sousa $^{2}$, P.V.P.; Sá ${ }^{3}$, F.S. \\ marcelobrandao@cfp.ufcg.edu.br
}

\section{Resumo}

As paisagens semiáridas são bastante complexas, as interações dos elementos do quadro natural produzem fisionomias distintas, entre estas, ocorrem os enclaves úmidos, áreas especiais, com características pedoclimáticas diferenciadas em relação ao seu entorno, com solos e composição florísticas e faunísticas específicas. Este trabalho tem como objetivo fazer um primeiro levantamento destas áreas no alto sertão paraibano, identificando-as e propondo métodos de identificação destes redutos através de suas características fisiográficas. Desta forma foi elaborado um cartograma identificando estes enclaves no alto sertão paraibano. $\mathrm{O}$ estudo e preservação destas áreas são de extrema importância, além de refúgios para diversas espécies da fauna e da flora, possuem vários mananciais hídricos e contribuem para a base econômica regional.
\end{abstract}

Palavras Chave: Enclaves, Paleoclimas, Paraíba.

\begin{abstract}
.
Semi-arid landscapes are very complex, the interection between elements of the natural setting create distincts physiognomies, among them, moist enclaves occur, special areas with different pedoclimatic characterstics of its surroundings, with specific soil and flora and fauna composition. This article aims to do a first survey of these areas in the hinterland, identifying them and proposing identification methods of these strongholds through their physigraphic caracteristics. For that, a cartogram identifying these strongholds was developed. The study and preservation of these areas are extremely important, besides being a refuge for many fauna and flora species, they have water sources and contribute for the local economy.
\end{abstract}

Keywords: Enclave, Paleoclimates, Paraíba.

\section{INTRODUÇÃO}

O semiárido nordestino é bastante complexo, a divulgação pela mass midia remete-nos a uma imagem triste, seca, melancólica, porém ao observar minuciosamente as peculiaridades da paisagem será possível perceber as suas complexas interações. Este é o caso específico do alto sertão paraibano, porém em algumas áreas as suas características geoambientais se distinguem de seu entorno, essa modificação da paisagem pode ser atribuída a um dos mais importantes

1. Marcelo Henrique de Melo Brandão, Unidade Acadêmica de Geografia. Centro de Formação de Professores. Universidade Federal de Campina Grande - UFCG, Cajazeiras-PB, Brasil.

2. Paulo Victor Paz de Sousa. Instituto Federal do Pará. Campus Marabá-IFPA, Marabá-PA, Brasil.

3. Francisco Severo de Sá, Município de Nazarezinho-PB, Brasil. 
pensamentos relacionados aos mecanismos padrões de distribuição da composição faunística e florística na América Tropical, a teoria dos refúgios e redutos. É esta teoria que pode explicar a ocorrência de uma vegetação de mata atlântica em pleno sertão paraibano. Com esta ocorrência toda a produção do espaço local se modifica, adequando-se a realidade local.

A região semiárida brasileira ocupa cerca de, $982.563,3 \mathrm{~km}^{2}$, em função das suas características edafoclimáticas sua cobertura vegetal é a Caatinga, formação florestal de baixo porte, nanofoleácea e coreácea, com ocorrência de espécies de cactáceas. Esta vegetação divide-se, de acordo com a sua composição florística e porte, em: caatinga arbórea, caatinga arbóreo-arbustiva e caatinga arbustiva. Neste ambiente atual é possível identificar alguns vestígios da ocorrência de climas mais úmidos no sertão paraibano. O objetivo deste trabalho é propor uma forma de identificar no alto sertão paraibano as possíveis áreas de ocorrência de redutos e refúgios florestais levando em consideração os aspectos relacionados a altitude, características pedológicas, geomorfológicas e algumas espécies vegetais que possam indicar climas mais úmidos no passado.

\section{METODOLOGIA}

As observações feitas através da ótica da teoria dos redutos e refúgios florestais demonstram a complexidade das paisagens semiáridas. No domínio das caatingas é possível identificar pequenas áreas diferenciadas, os enclaves úmidos ou subúmidos. Estes enclaves são explicados através das variações climáticas ocorridas durante o período Quaternário, onde as oscilações climáticas ocorridas na alternância de períodos glaciais e interglaciais modificavam as características climáticas da região, consequentemente a cobertura vegetal se adequava às condições reinantes.

A dispersão de espécies da fauna e da flora regional ocorria em períodos de expansão ou retração de acordo com as características mesológicas. Desta forma, as espécies de clima úmido se expandiam quando o clima úmido predomina na região enquanto as espécies com características xerofíticas se retrairiam, diferentemente, se ocorre uma variação climática para climas mais secos, as espécies adaptadas aos climas mais secos se expandiam enquanto as espécies mais úmidas se retrairiam, restringindo a sua ocorrência apenas em áreas onde as condições pedoclimáticas fossem adequadas a sua manutenção. Teoricamente a teoria dos redutos e refúgios enfatiza o período Quaternário e as suas alternâncias climáticas (climas quentes x climas frios) como mecanismo destes momentos de expansão e retração, porém em observações feitas em campo, é possível perceber que estes processos de expansão e retração podem ser mais antigos, chegando mesmo ao final do período Terciário (Mioceno/Plioceno).

Para a elaboração do cartograma que representa as prováveis áreas de ocorrência de enclaves úmidos, foram levados em consideração os seguintes fatores: 
A altimetria, o fator altitude é fundamental para a ocorrência destas áreas, este fator influencia diretamente na dinâmica atmosférica local, formando os enclaves úmidos. Sobre isso Cabral et al (2004, p. 33) faz o seguinte comentário: “é a Serra do Comissário, situada ao norte de Souza, na Paraíba, que apresenta altitudes superiores a $600 \mathrm{~m}$ e, devido à diferença altimétrica, suas porções mais elevadas gozam de condições climáticas bem mais amenas que as reinantes na área baixa circundante". No método de identificação proposto, para afastar a possibilidade da dúvida entre a ocorrência da caatinga arbórea com as áreas de enclaves úmidos, estabeleceu-se a cota altimétrica de $750 \mathrm{~m}$.

Os indicadores pedológicos: é possível observar a existência de paleossolos com características estruturais completamente diferenciadas dos solos desenvolvidos em climas áridos e semiáridos, na região estudada predominam os bruno não cálcicos (Luvissolos). Nas áreas de enclaves úmidos podem ser encontradas camadas de solos bem desenvolvidos, com a identificação dos três horizontes (A, B e C). Nas áreas da pesquisa foi possível encontrar os Vertissolos, Argissolos Vermelho Amarelo, os Neossolos Regolíticos, Neossolos Litólicos Eutróficos.

Os indicadores geomorfológicos: observa-se nas encostas superiores destas áreas a ocorrência de colúvios pedogeneisados, o que demonstra um forte processo erosivo, onde a ação pluvial se fez mais intensa em um passado geológico relativamente recente (Pliopleistoceno). Além dos colúvios pedogeneisados, faz-se presente em algumas áreas restritas das serras (base e alguns afloramentos no topo da serra) os processos de evorsão, onde o desgaste da rocha foi elaborado através do movimento turbilhonar sobre as rochas do fundo do rio. Atualmente a drenagem dos riachos que existem nestas serras não possui competência hídrica suficiente para elaborar as "marmitas" que existem, desta forma somente um rio com drenagem perene e com alta competência erosiva poderia provocar este desgaste nas rochas.

Os indicadores botânicos: A cobertura vegetal predominante nestas áreas apresenta-se de forma bastante diferenciada. É possível identificar uma diversidade na cobertura vegetal incluindo desde a caatinga arbustiva, caatinga arbustiva-arbórea, a caatinga arbórea-arbustiva, a mata seca e mata subúmida seca. Dentro do contexto das caatingas, estas áreas funcionam como um refúgio florestal, pois nelas, ocorrem espécies que não são características de climas semiáridos. A explicação para a existência destas espécies vegetais pode está centrada na possibilidade de interligações florestais pretéritas unindo a Floresta Amazônica à Floresta Atlântica (AB'SÁBER, 1977; VANZOLINI, 1986; BIGARELLA et al, 1975). A hipótese mais aceita sobre a gênese vegetacional dos refúgios e redutos úmidos e subúmidos relaciona-se às variações climáticas ocorridas durante o Pleistoceno (últimos 2 milhões - 10.000 anos), as quais puderam permitir que espécies da Floresta Atlântica adentrasse os domínios da caatinga. Em um levantamento florístico na Serra da Santa Catarina GADELHA NETO \& BARBOSA (2012) identificam espécies de climas 
mais úmidos que o reinante no alto sertão da Paraíba, estas espécies podem servir como identificadoras de áreas de redutos e refúgios, são elas: a Jussara (Solanum asperum Rich), o Inharé (Brosimun guianense (Aubl)), a Xylosma sp, além de serem observados em algumas áreas a ocorrência de pteridófitas, que não são características dos climas semiáridos.

\section{RESULTADOS E DISCUSSÃO}

Ao observar a área de estudo, o alto sertão paraibano, analisando os indicadores selecionados na metodologia do trabalho (altimetria, indicadores pedológicos, indicadores geomorfológicos e os indicadores botânicos) associado às observações em campo foi possível elaborar o seguinte cartograma:

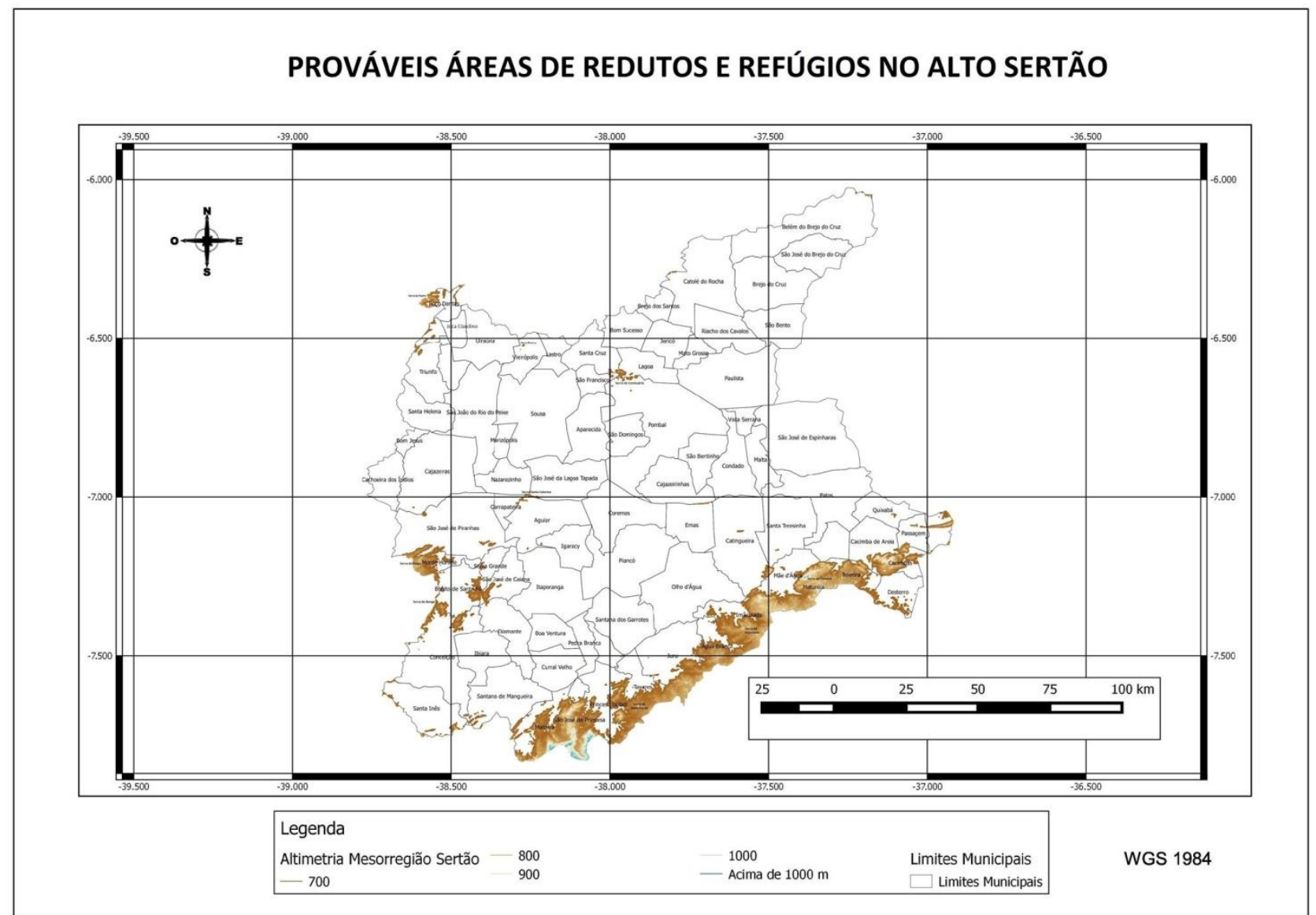

Cartograma: Prováveis áreas de redutos e refúgios no alto sertão paraibano (2016).

É possível observar uma concentração dos enclaves úmidos na parte meridional, com a ocorrência nas serras do Teixeira, Imaculada e da Baixa Verde. Na porção sudoeste a ocorrência destes redutos localiza-se nas serras do Bongá e do Braga. Pontualmente na parte setentrional é possível identificar as serras do Padre, Branca e do Comissário. Na parte central da área de estudo a existência da serra da Santa Catarina é um exemplo típico destas áreas diferenciadas. 


\section{CONSIDERAÇÕES FINAIS.}

O estudo destas áreas especiais tem uma grande importância regional, pois as mesmas constituem de áreas de refúgio para espécies animais e redutos para as formações vegetais, além de servirem de corredores ecológicos para a manutenção da fauna e flora regionais. Ao mesmo tempo, possuem importância estratégica na manutenção dos mananciais hídricos para os municípios inseridos nestas áreas. Em função de suas características pedoclimáticas possuem importância econômica na região, pois é possível observar que são áreas com grande utilização agropecuária. Em virtude de suas características diferenciadas podem ser utilizadas como atrativos para o desenvolvimento de um turismo sustentável de base local, gerando uma renda extra para as comunidades. Desta forma, existe a necessidade urgente de uma política de gestão espacial, pois nas áreas de ocorrência dos enclaves úmidos o uso e a ocupação do solo de maneira irregular vêm provocando sérios processos de degradação ambiental, contribuindo com a diminuição ou até mesmo a extinção de espécies animais e vegetais.

\section{REFERÊNCIAS.}

ANDRADE-LIMA, D. Present day Forest refuges in Northeastern Brazil. Biological diversification in the tropics. p. 245-254. New York, Columbia University Press, 1982.

AB'SÁBER, A. N. Brasil: paisagens de exceção: o litoral e o pantanal Mato-grossense: patrimônios básicos. Cotia, SP: Ateliê Editorial, 2006.

. Os Domínios morfoclimáticos na América do Sul. Geomorfologia. 52, 1-2., 1977.

Espaços ocupados pela expansão dos climas secos da América do Sul, por ocasião dos períodos glaciais quaternários. Paleoclimas. 3, 1-18, 1977.

BIGARELLA, J.J. Variações climáticas no Quaternário e suas implicações floristicas no

Paraná. Boletim Paranaense de Geografia, Curitiba, vol. 10, nº 15, 1964.

BIGARELlA, J. J.et all. Considerações à respeito das mudanças paleoambientais na distribuição de algumas espécies vegetais e animais no Brasil. Anais da Academia Brasileira de Ciência. 47, p. 411-464.1975.

CABRAL, Jaime J. S. P. et al. Recursos Hídricos e os Brejos e Altitude. IN: TABARELLI, Marcelo; PORTO, Kátia C. \& CABRAL, Jaime J. P. (orgs). Brejos de Altitude em Pernambuco e Paraíba: história natural, ecologia e conservação. Brasília. Ministério do Meio Ambiente. 2004.

FERRAZ, M. M. E. Variação florístico vegetacional na região do vale do Pajeú, Pernambuco. Dissertação de Mestrado. Universidade Federal Rural de Pernambuco, Recife, 1994. 
GADELHA NETO, P. C. \& BARBOSA, M. R. V. Levantamento Florístico da Serra de Santa Catarina - PB: árvores e arbustos. Acta Botânica Brasileira. 2012. No prelo

LINS, R. C. As áreas de exceção do Agreste de Pernambuco. Sudene, Recife-PE, 1989.

OLIVEIRA, P. E. Esfriamento glacial e expansão de florestas úmidas e frias no último máximo glacial da Amazônia. Anais do 51 Congresso Nacional de Botânica, Brasília. 2000.

PARAÍBA. Plano Diretor dos Recursos Hídricos do Estado da Paraíba. PDRHPB. Bacia do Rio do Peixe. João Pessoa, 2006. ; Agência Executiva de Gestão das Águas do Estado da Paraíba.AESA. Plataforma de

Coletas de Dados Meteorológicos. João Pessoa, 2010. Disponível em:< http://www.aesa.pb.gov.br/meteoro/pcds.php>, acesso em Junho de 2010.

SOUSA, Paulo Victor Paz de. A serra da Santa Catarina: Um enclave subúmido no sertão paraibano e a proposta de criação de uma unidade de conservação. Fortaleza-CE. 2011. Dissertação de Mestrado. Universidade Federal do Ceará. 2011.

SOUZA, M. J. N. \& OLIVEIRA, V. P. V. Os enclaves Úmidos e Sub-úmidos do Nordeste Brasileiro. Mercator - Revista de Geografia da UFC, ano 05, nº 9, 2006.

TABARELlI, Marcelo; PORTO, Kátia C. \& CABRAL, Jaime J. P. (orgs). Brejos de Altitude em Pernambuco e Paraíba: história natural, ecologia e conservação. Brasília. Ministério do Meio Ambiente. 2004.

VANZOLINI, P. E. Paleoclimas e especiação em animais da América do Sul. São Paulo: Associação brasileira de estudos do Quaternário, 1986. (Publicação Avulsa).

VASCONCELOS-SOBRINHO, J. As regiões naturais do Nordeste, o meio e a civilização. p. 441. Conselho de Desenvolvimento de Pernambuco, 1981.

ViadanA, A. G. \& CAVAlCANTI, A. P. B. A Teoria dos Refúgios Florestais Aplicada ao Estado de São Paulo. Revista da Casa de Geografia de Sobral, Sobral, CE, Vol 8/9, n.1, pág. 6180, 2007.

Recebido em: 14/08/2016

Aceito para publicação em: 01/10/2016 